\title{
Peyzaj Alanlarındaki Sulama Projelerinin 3 Boyutlu Tasarımı: Bursa İli Maltepe Su Deposu Peyzaj Alanı Örneği
}

\author{
Oğuzhan Alkan ${ }^{1} \quad$ Kürşad Demirel ${ }^{1^{*}}$ \\ ${ }^{1}$ Çanakkale Onsekiz Mart Üniversitesi Mimarlık ve Tasarım Fakültesi, Peyzaj Mimarlığı Bölümü, 17020, ÇANAKKALE \\ *Sorumlu yazar: kdemirel@ comu.edu.tr \\ ${ }^{1}$ https://orcid.org/0000-0003-4045-3218, ${ }^{2}$ https://orcid.org/0000-0002-2029-5884
}

Geliş Tarihi: 27.01.2020

Kabul Tarihi: 06.05.2020

\section{$\ddot{O} z$}

Peyzaj alanlarına ilişkin yapılan tasarımlarının görsel olarak daha iyi görünebilmesi için, kâğıt üzerinde çizilen iki boyutlu projeler yerine teknolojinin gelişmesiyle birlikte bilgisayarlarda 3 boyutlu olarak daha kolay ve hızlı tasarlanabilmektedir. Projelerin üç boyutlu olarak gösterilmesi projeyi tasarlayan kişilere, uygulayıcılara ve kullanıcılara büyük kolaylıklar sağlamaktadır. Ülkemizde yapılan peyzaj alanlarındaki sulama sistemi projeleri genellikle profesyonel kişilerce tasarlanmadığından uygulama sonrası problemler ortaya çıkmaktadır. Bu çalışmada, Bursa İl'inde Maltepe Su Deposu Çevre Düzenleme Peyzaj Projesinde sulama sisteminin yeniden ele alınarak üç boyutlu olarak tasarlanması amaçlanmıştır.

Çalışma sonucunda söz konusu alanda sulama sistemi toprak, bitki örtüsü, eğim, su kaynağı vb. parametreler göz önüne alınarak yeniden tasarlanmıştır. Buna ilaveten, sulama sisteminin tüm parçaları 3DsMAX programında üç boyutlu olarak çizilmiştir. Ayrıca, suyun dağılımının da üç boyutlu olarak animasyonunun gösterimi de yapılmıştır. Yapılan bu çalışma ile yapısal ve bitkisel üç boyutlu tasarımın yanında su kaynağından bitkiye ulaşıncaya kadar sulama sisteminin tüm parçalarının üç boyutlu olarak gösterilmesi hazırlanan projelere büyük katkı sağlayacaktır.

Anahtar Kelimeler: Tasarım, sulama, Bursa, peyzaj

\section{D Design of Irrigation Projects in Landscape Areas: Maltepe Water Tank Landscape Area in Bursa Province \\ Abstract}

For the designs made in landscape areas to be visually better, instead of two-dimensional projects drawn on paper, with the development of technology, it can be designed more easily and faster in 3-dimensional in computers. Showing the projects in three dimensions provides great convenience to the people, practitioners and users who designed the project. Since irrigation system projects in landscaping areas in our country are not designed by professional people, problems arise after application. In this study, it was aimed to reconsider the irrigation system in three dimensions in Maltepe Water Reservoir Landscaping Landscape Project in Bursa Province.

As a result of the study, the irrigation system in the area in question is soil, vegetation, slope, water source, etc. redesigned considering the parameters. In addition, all parts of the irrigation system are drawn in 3D in the 3DsMAX program. Also, an animation of the distribution of water in three dimensions was made. With this study, the three-dimensional display of all parts of the irrigation system from the water source until the plant reaches the structural and vegetative three-dimensional design will contribute greatly to the prepared projects.

Keywords: Design, irrigation, Bursa, landscape

\section{Giriş}

Sanayileşmenin artmasıyla birlikte betonlaşma ve karbon salınımında gözlenmiş olan artış beraberinde günümüzün başta gelen problemi olan küresel 1sınmayı ortaya çıkarmıştır. Birleşmiş Milletler (BM) verilerine göre küresel ısınmanın yol açtığı problemlerden olan yağışların giderek azalması, buharlaşmanın artması ve beraberinde ortaya çıkan nüfus artışından dolayı suyun hızlı tüketimi, plansızlıktan kaynaklanan çevre kirliliği temiz su kaynaklarını giderek tüketmektedir. 2025 yılında 2 milyar ve 2050 yılında 7 milyar insanın susuzlukla karşı karşıya kalacağını tahmin edilmektedir (Aydın, 2019).

Günümüzde; akarsu, göl, yeraltı suyu olarak gördüğümüz ve yeşil alanları besleyen sulak alanların gelecek nesillerin karşısına kurak araziler olarak çıkması olasıdır. Suyun azalmasından dolayı ortaya çıkan ve giderek artan yeşil alanların kaybı da bu durumun beraberinde gelmektedir. 
Ülkemizin en büyük kenti olan İstanbul'da uzmanlar kişi başına düşen aktif yeşil alanın 1 metre kareye kadar düştügünü belirlemişlerdir. Günümüzde kendini göstermeye başlamış olan peyzaj alanlarının azalması gelecekteki en önemli problemlerden biri olması kaçınılmazdır. Yeşil alanların azalması beraberinde daha büyük sorunları getirecektir (Demircan, 2017).

Ülkemizde, peyzaj alanlarındaki sulama sistem projeleri genel olarak arazinin ve bitki örtüsünün istekleri göz önüne alınmadan ve konusunda uzman olmayan kişiler tarafindan tasarlanmaktadır. Bir alana ait yapılan peyzaj projesi ne kadar iyi ve kaliteli olursa olsun, eğer alana uygun ve doğru bir sulama sistemi projesi yapılmadıysa ortaya farklı farklı sorunlar (bitkilerin kuruması, sadece yeşil alan değil tüm yerlerin sslatılması, tüm alanın eşit sulanmaması, su israfı vb.) meydana gelecektir. Meydana gelebilecek bu türlü sorunların ortadan kaldırılması için sulama sistemini projeleyecek uzmanın su, toprak ve bitki arasındaki ilişkileri iyi bilen ve bununla birlikte iyi bir sulama sistemi tasarımını sağlayabilecek bilgi birikimine sahip olması gerekmektedir (Demirel ve ark., 2018).

Peyzaj alanlarında bitki örtüsünün canlılığının korunabilmesi; sulama suyunun etkin kullanılarak peyzaj alanlarında eş su dağılımının sağlanmasına, alana ve iklim şartlarına uygun doğru bir sulama programının yapılmasına ve özellikle sulama sistemini projelendirecek peyzaj mimarı veya sulama uzmanının bilgi birikimine bağlıdır. Ülkemizde peyzaj alanlarında tasarlanan sulama projelerinde yapılacak sulamalar hala toprağın 1slatılması olarak düşünülmekte, bitkilerin ve toprağın istekleri göz önüne alınmamaktadır. Ayrıca, sulama sistemlerinin doğru tasarlanmadığı alanlarda su israfı kaçınılmaz olmaktadır (Demirel ve ark., 2018). Ülkemizde peyzaj alanlarındaki sulama sistemi ile ilgili olarak sulama sistemlerindeki eksikliklerin belirtilmesi ve alana uygun proje tasarlanmasi üzerine yapılan çalışmalar bulunmaktadır (Demirel ve ark., 2006; Küçüksayan ve ark., 2011; İşbilir ve Erdem, 2012; Demirel ve ark., 2018; Gönül Altay, 2019). Bu konu ile yapılan çalışmaların arttırılması ve geliştirilmesi gerekmektedir.

Günümüzde peyzaj alanlarına ait tasarımlar bilgisayar ortamında yapılmaktadır. Mimarların en çok kullandığı modelleme programları arasında Blender, Archicad, Maya, Sketchup ve 3DsMax gösterilebilir (Öztürk, 2014). Peyzaj projelerinde en çok tercih edilen program 3DsMax'dır. Autodesk firmasına ait olan bu program hem mimarlar hem de mühendisler tarafından oldukça tercih edilmektedir. Programın tercih edilme sebeplerinin başında materyal editör kısmının oldukça gelişmiş olması ve hazır materyale ücretsiz ulaşımın oldukça kolay olmasıdır. Ayrıca, modelleme ile animasyon işlemi de yapılabilmektedir (Öztürk, 2014). Ülkemizde peyzaj alanlarında sulama sistem projelerini değerlendiren çalışmalara az da olsa rastlanılmasına rağmen, üç boyutlu olarak tasarımının yapıldığı bir çalışmaya rastlanılmamıştır.

Projeyi hazırlayan uzmanın (peyzaj mimarı/sulama mühendisi) yaptığı projeyi kullanıcı veya alıcı kişilerin daha iyi anlayabilmesi açısından hazırladığı yapısal ve bitkisel elemanları ile sulama sistemini de üç boyutlu olarak gösterebilmesi işini kolaylaştıracaktır. Bu çalışmada, örnek olarak seçilen Bursa İlinde Maltepe Su Deposu Çevre Düzenleme Peyzaj Projesinde sulama sistemi toprak, bitki örtüsü, eğim, su kaynağı, engeller vb. parametreler göz önüne alınarak yeniden üç boyutlu olarak tasarlanmıştır. Buna ilaveten, sulama sisteminin tüm parçaları üç boyutlu olarak çizilmiş ve suyun dağılımının da üç boyutlu olarak animasyonunun gösterimi yapılmıştır. Bu çalışmada; i) günümüzün ilerleyen teknolojisi ile birlikte var olan ve anlaşılması zor olan peyzaj sulama sistemi projelerinin kullanıcıların/uygulayıcıların gözünde daha net ve anlaşılabilir bir şekle dönüştürülmesi, ii) üç boyutlu olarak detaylı hazırlanmış olan sulama sistemi projelerinin ileride anlaşılamadığından dolayı ortaya çıkacak olan kullanıcı/müşteri memnuniyetsizliklerinin ortadan kaldırılması, iii) projeyi tasarlayan peyzaj mimarlarının alıcıya/müşteriye yapılan sunum sırasında daha anlaşılabilir bir proje sunarak ticari olarak farkındalığın yaratılması; iv) günümüzün olmazsa olmazı olan teknoloji ve piyasalardaki sıradanlığı ortadan kaldırıp müşteri ve projenin iç içe olması amaçlanmıştır.

\section{Materyal ve Yöntem \\ Çalıșma Alanı}

Bursa, yaklaşık 3 milyon nüfuslu Türkiye'nin dördüncü büyük şehridir. Bulunduğu Marmara bölgesinde ise ikinci büyük şehir olarak yer almaktadır. Bitki örtüsü, özel konumundan kaynaklı olarak çevrede bulunan büyük şehirlere yakınlığı ve en önemlisi olan istihdam imkânının fazlalığı nedeniyle oldukça fazla göç almaktadır. Nüfusun her geçen gün artışı, insanların yaşamsal alanlarda 
kendilerini dinlendirerek şehrin koşuşturması içerisinde nefes alabilecekleri yeşil alanların önemini biraz daha ortaya koymaktadır. $\mathrm{Bu}$ nedenle hali hazırda var olan yeşil alanların ve şehrin gelişmesinden kaynaklı ortaya çıkan yeşil alanların doğru planlanıp insanların hizmetine sunmak önemli bir görev olarak karşımıza çıkmaktadır. Bu amaçlar esas alınarak uygulama alanı Bursa İli Maltepe İlçesindeki Maltepe Su Deposu olarak belirlenmiştir. Söz konusu alan 40¹0' 39" N ve $29^{\circ} 06^{\prime} 05$ "E koordinatlarında bulunmaktadır. Ayrıca $6388 \mathrm{~m}^{2}$ alana sahiptir (Şekil 1).

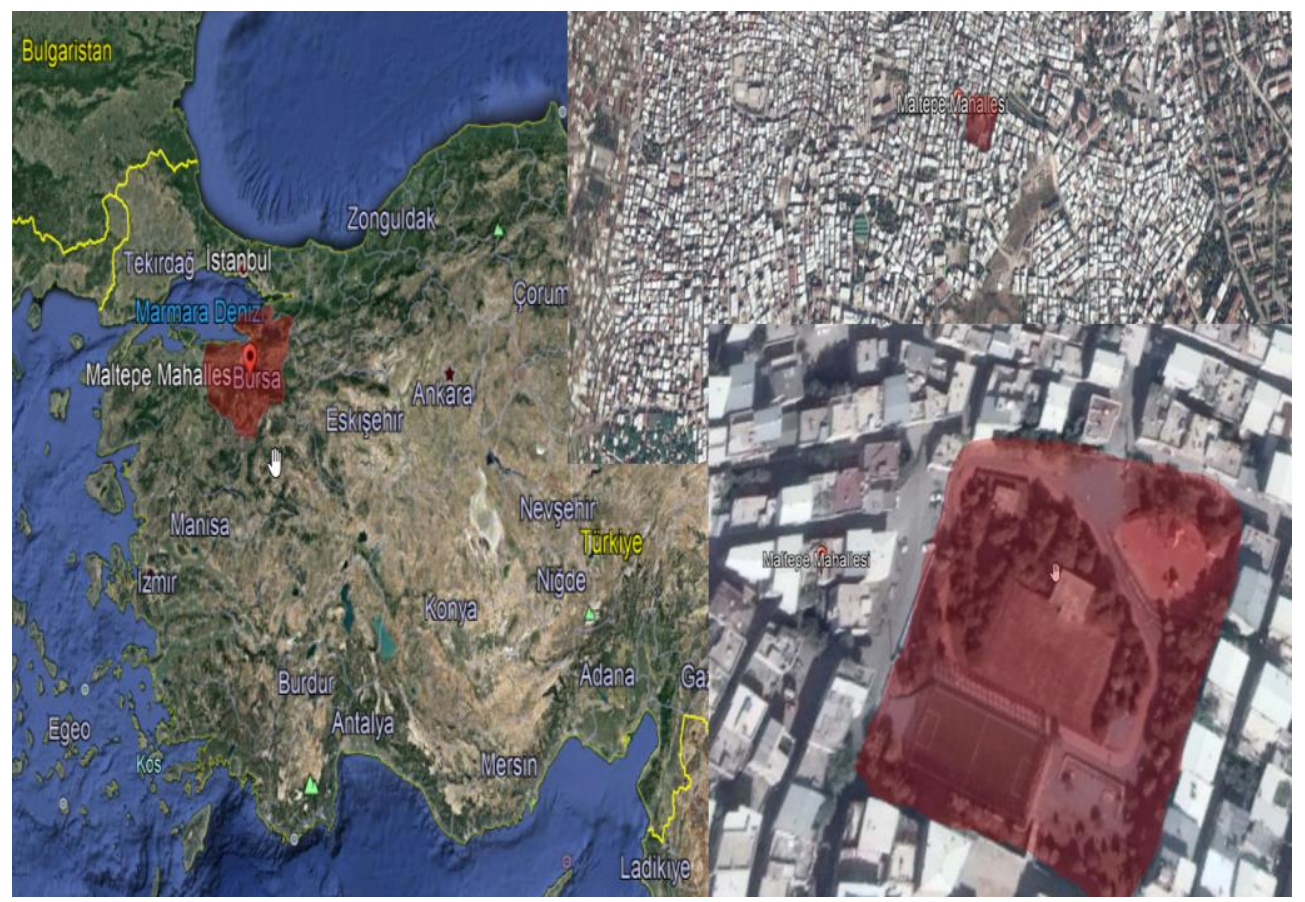

\section{Şekil 1. Deneme alanı (URL 1)}

Uygulama alanına ait olan ve yeniden tasarlanan yapısal ve ölçülendirme projesi Şekil 2'de peyzaj projesi ise Şekil 3'te gösterilmiştir. Deneme alanın mevcut peyzaj projesi incelenmiş ve yeniden tasarlanmıştır. Sulama sistemi projesi peyzaj projesinin belirlenmesi ardından çizilerek gerekli hesaplamalar yapılmıştır (Orta, 2009). Çalışma alanındaki toprak bünyesi tınlı olarak belirlenmiştir.
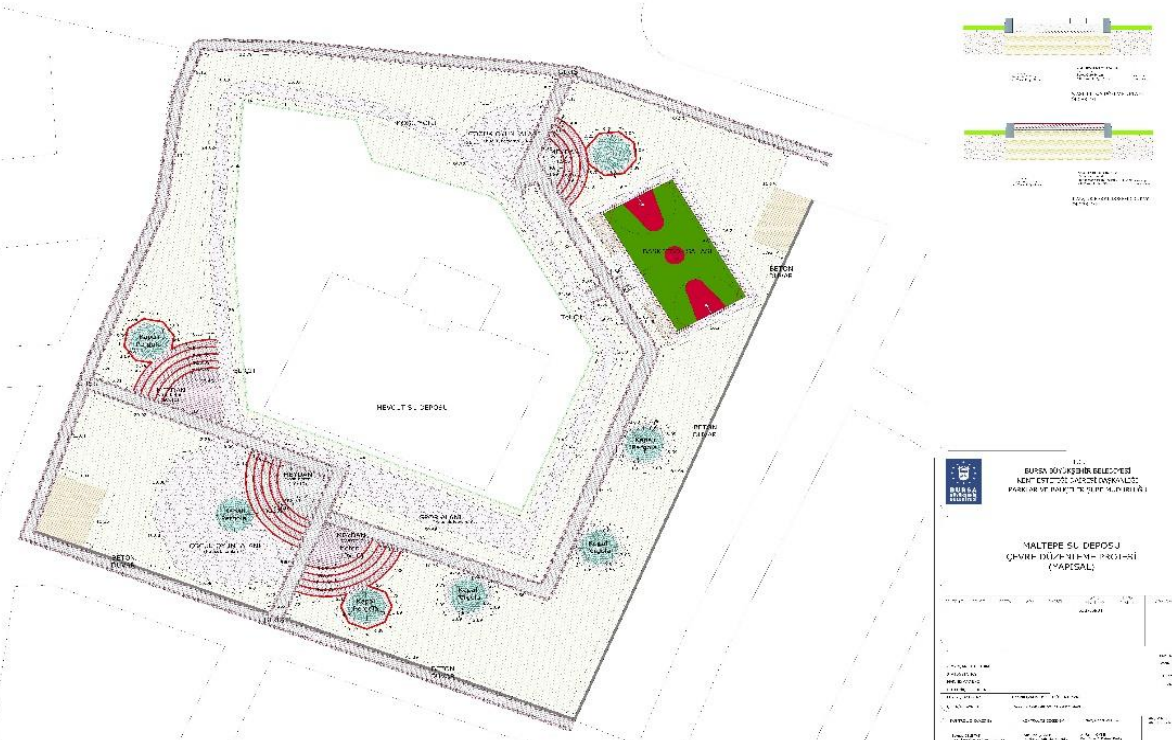

Şekil 2. Maltepe Su Deposu'na ait örnek yapısal projesi 

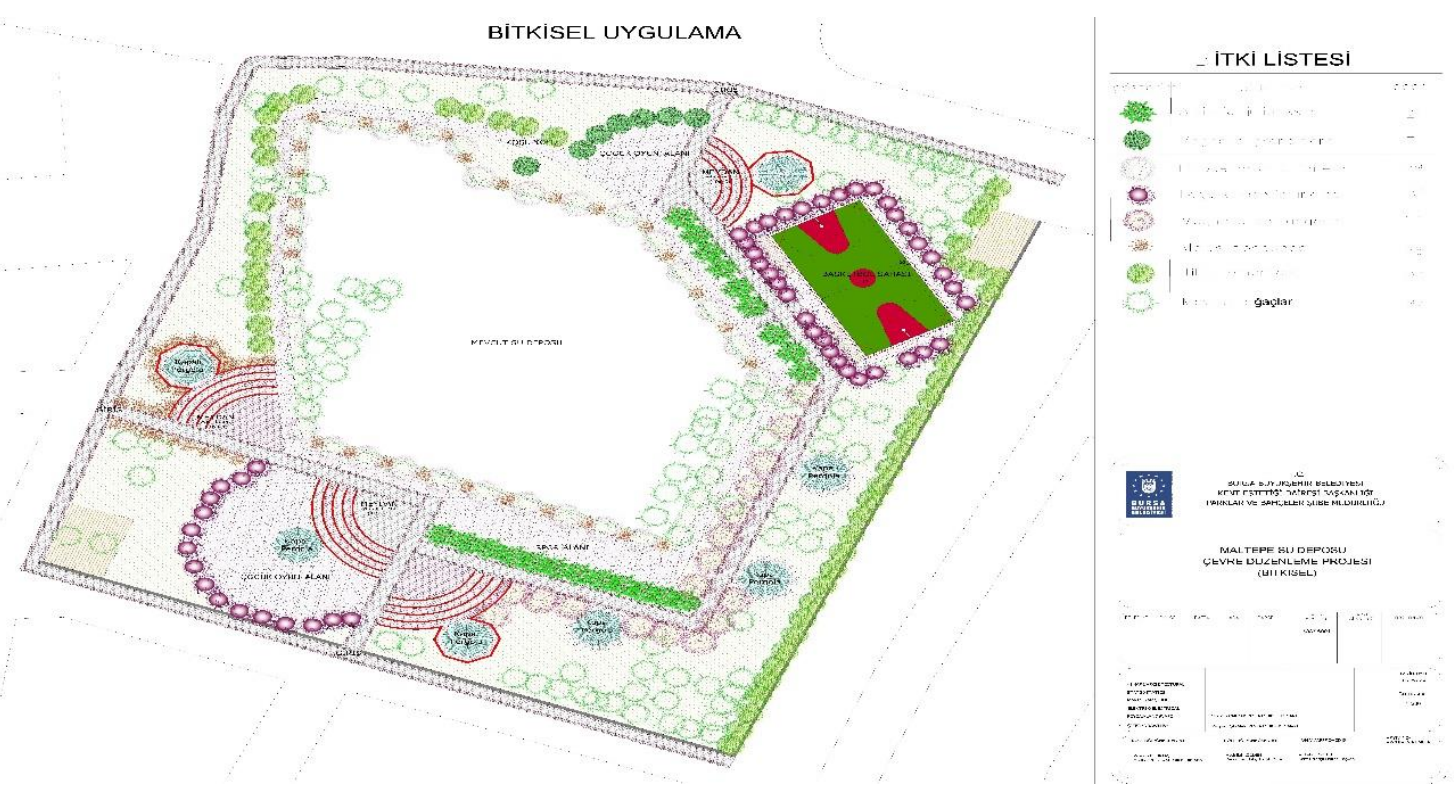

Şekil 3. Maltepe Su Deposu'na ait örnek peyzaj projesi

\section{Sulama Sisteminin Üç Boyutlu Olarak Tasarımı}

Alana uygun sulama projesi yapıldıktan sonra sulama sisteminin tüm parçaları ve sulama sisteminin tamamı üç boyutlu olarak görselleştirilmiştir. Çalışma kapsamında yapılan görselleştirme işleminde, görüntü kalitesi açısından en gerçekçi formu yakalanabileceği 3DsMax programı kullanılmıştır. Alana uygun sulama projesi yapıldıktan sonra modelleme işlemine geçilmiştir. Modelleme işlemi sırasında kullanılmış olan 3DsMax programına hazırlanmış olan peyzaj projesi aktarılmıştır. Projedeki yeşil alanlar, koşu yolları, yürüme yolları, araç yolları ve geri kalan binalar modellenerek alanda bulunması gereken koordinatlara oturtulmuştur. Daha sonra yeşil alanlarda kullanılan bitkiler belirlenerek projede belirlenmiş noktalara getirilerek konumlandırılmıştır. $\mathrm{Bu}$ aşamanın ardından projede kullanılmış olan şehir mobilyaları, elektrik direkleri, çöp kutuları ve yollarda kullanılmış olan materyaller projedeki gibi uygun şekilde konumlandırılmıştır. Bu aşamanın ardından sulama projesi başka bir 3DsMax dosyasında modellenmeye başlanmıştır.

Önce projede kullanılmış olan malzemeler belirlenmiş ve daha sonra materyallerin uygun ölçüleri araştırılmıştır. $\mathrm{Bu}$ aşamanın ardından malzemelerin modellenmesi işlemine geçilmiştir. Ölçülerine uygun şekilde projedeki (Ana borular, lateral borular, vanalar, nozullar, başlıklar vb.) materyaller modellenmiştir. Modellenmiş olan peyzaj projesinin üzerine modellenmiş olan sulama projesi getirilerek çakıştırma işlemi yapılmış ve yerleştirilmiştir. $\mathrm{Bu}$ işlemin ardından programın modlarından olan vray (malzeme atama modu) moduna geçilmiştir. Programın bu modda seçilmesinin amacı vray materyallerinin işlem bitimi ardından alınacak rander (görselleştirme) işleminde gerçekçiliği daha çok yansıtmasıdır. Vray modunda materyaller örneğin yola döşenmiş olan kilit parke taşı ya da boruların PVC plastik malzemesi tek tek internet üzerinden vray materyal sitelerinden bulunarak kullanılmıştır.

$\mathrm{Bu}$ işlem indirilmiş olan materyalin programın içerisine atılarak materyal ekranından getirilip modelin üzerine yerleştirilmesiyle gerçekleşmiştir. $\mathrm{Bu}$ işlem alandaki her maddeye uygulanmıştır. Maddeler tek tek seçilerek programın yan sekmesinden UVM map arayüzüne geçilerek ve materyaller için seçilmiş olan yüzey malzemeleri her cisim için ayrı ayrı üzerine giydirilerek X, Y, Z koordinatlar doğrultusunda boyutlandırması yapılmıştır. Yollar X:111 Y:111 Z:111 olarak belirlenmiştir. Geri kalan cisimler boyutlarına göre bu şekilde ayrı ayrı giydirilmiştir. Daha sonra alandan alınan randerin hangi mevsim ve zaman diliminde olacağına yönelik güneş ve koordinat ayarlamaları yapılmıştır. Güneş her yarım kürede ve her saat diliminde farklı açılardan geleceği için alanın koordinatı göz önüne alınarak ışık ayarlaması yapılmıştır. Daha sonra rander alınmayı düşünülen açılara kamera tek tek yerleştirilerek yakınlık uzaklık ayarları ve kamera özellikleri belirlenmiştir. 
Hazırlanmış olan animasyon işleminin gerçekçiliğini artırabilmek için modellenip yerleştirilmiş olan boruların içerisine su ilave edilmiştir. Bu ilave edilen su gerçekçilik olabilmesi için programın komutları kullanılarak yerçekimi, suyun boru içerisindeki takibi, akışkanlığı ve saydamlık uygulaması yapılmıştır. Yağmurlama başlıkları önce suyun kapalı olduğu haldeki şekli ve vananın açılmasının ardından suyun basıncı ile başlığın itilerek yukarı çıkmış hali 3 boyutlu olarak görüntülenmiştir.

\section{Bulgular ve Tartışma}

\section{Maltepe Su Deposunun Sulama Sistem Tasarımı}

Çalışma alanında daha önce 1slah çalışması yapılmamasından kaynaklı olarak alanın tamamında yabani otlanma ve çalılar görülmektedir. Alanda çevre sakinlerinin düzensiz olarak ektiği yer yer meyve ağaçları (Malus spp.), çam türleri (Pinus brutia, Pinus pinea) ve yabani atkestanelerine (Aesculus hippocastanum) rastlanmaktadır. Projelendirme yapılırken mevcut ağaçların korunmasına özen gösterilerek tasarım yapılmıştır.

Çalışma alanında sulama sistemi projelenmesinde kullanılan veriler Çizelge 1'de gösterilmiştir. Ayrıca alanda maksimum sulama süresi 12 saat olarak belirlenmiştir. Alanın projelendirilmesinde yapılan sulama tasarımında kaynak olarak şebeke suyu kullanılmıştır. Alanda farklı başlıklar kullanıldığından dolayı yağmurlama hızı, alanda kullanılan tüm başlıkların ortalaması alınarak $15 \mathrm{~mm} \mathrm{~h}^{-1}$ hesaplanmıştır. Sulama sistemine ait ön projeleme faktörlerine ait veriler Çizelge 2'de sunulmuştur.

Çizelge 1. Sulama sistemi tasarlanırken kullanılan veriler

\begin{tabular}{|c|c|c|c|c|c|c|}
\hline $\begin{array}{c}\text { ET } \\
(\mathrm{mm} \text { gün }\end{array}$ & $\begin{array}{c}\text { D } \\
(\mathrm{cm})\end{array}$ & $\begin{array}{c}\text { Ry } \\
(\%)\end{array}$ & $\begin{array}{c}\text { Toprak } \\
\text { tekstürü }\end{array}$ & $\begin{array}{c}\mathrm{dk} \\
\mathrm{mm} \mathrm{m}^{-1}\end{array}$ & $\begin{array}{c}\mathrm{I} \\
\mathrm{mm} \mathrm{h}^{-1}\end{array}$ & $\begin{array}{c}\mathrm{Q} \\
\mathrm{L} \mathrm{s}^{-1}\end{array}$ \\
\hline 6 & 30 & 30 & Tinlı & 160 & 23 & 2 \\
\hline
\end{tabular}

ET: Bitki su tüketimi, D: Etkili kök derinliği, Ry: Kullanılabilir su tutma kapasitesinin tüketilmesine izin verilen kısmı, dk: Kullanılabilir su tutma kapasitesi, I: Toprağın infiltrasyon hızı, Q: Su kaynağı debisi

Çizelge 2. Sulama sistemine ait ön projeleme faktörleri

\begin{tabular}{|c|c|c|c|c|c|c|c|}
\hline $\begin{array}{c}\mathrm{Iy} \\
\left(\mathrm{mm} \mathrm{h}^{-1}\right)\end{array}$ & $\begin{array}{c}\mathrm{dn}_{\max } \\
(\mathrm{mm})\end{array}$ & $\begin{array}{c}\mathrm{SA} \\
(\mathrm{gün})\end{array}$ & $\begin{array}{c}\mathrm{dn} \\
(\mathrm{mm})\end{array}$ & $\begin{array}{c}\mathrm{dt} \\
(\mathrm{mm})\end{array}$ & $\begin{array}{c}\mathrm{Ta} \\
(\mathrm{dak})\end{array}$ & $\begin{array}{c}\text { Nmax } \\
(\text { adet })\end{array}$ & $\begin{array}{c}\text { Nmin } \\
(\text { adet })\end{array}$ \\
\hline 15 & 14.4 & 2 & 12 & 15 & 60 & 11 & 2 \\
\hline
\end{tabular}

Iy: Yağmurlama hızı, $\mathrm{dn}_{\max }$ : Maksimum net sulama suyu miktarı, SA: Sulama aralığı, dn: Net sulama suyu miktarı,

dt: Toplam sulama suyu miktarı, Ta: Sulama süresi, Nmax: Maksimum işletme birimi, Nmin: Mimimum işletme birimi

Çizelge 3. Lateral borulara ait veriler

\begin{tabular}{|c|c|c|c|c|c|c|c|c|c|c|}
\hline \multirow{2}{*}{$\begin{array}{l}\text { Lateral } \\
\text { Verileri }\end{array}$} & \multicolumn{10}{|c|}{ İşletme Birimi } \\
\hline & L1 & L2 & L3 & L4 & L5 & L6 & L7 & L8 & L9 & L10 \\
\hline $\begin{array}{l}\text { Uzunluk } \\
\text { (m) }\end{array}$ & 72.5 & 66.5 & 52.5 & 122 & 60 & 74.5 & 48 & 52.5 & 140 & 72 \\
\hline $\begin{array}{l}\text { Başlık } \\
\text { Sayıs1 } \\
\text { (adet) }\end{array}$ & 23 & 22 & 19 & 42 & 30 & 38 & 34 & 35 & 31 & 28 \\
\hline $\begin{array}{l}\text { Debi } \\
\left(\mathrm{L} \mathrm{s}^{-1}\right)\end{array}$ & 0.90 & 0.94 & 0.92 & 1.53 & 1.41 & 1.42 & 0.87 & 0.86 & 0.84 & 0.82 \\
\hline $\begin{array}{l}\text { Boru Çap1 } \\
(\mathrm{mm})\end{array}$ & 32 & 32 & 32 & 40 & 40 & 40 & 32 & 32 & 32 & 32 \\
\hline $\begin{array}{c}\text { Giriş } \\
\text { Basınc1 } \\
\text { (bar) }\end{array}$ & 4 & 3.1 & 3.3 & 3.5 & 3 & 3.8 & 3.3 & 2.3 & 2.3 & 3.7 \\
\hline $\begin{array}{l}\text { Vana Anma } \\
\text { Çap1 } \\
\text { (inç) }\end{array}$ & $1 "$ & $1 "$ & $1 "$ & $1^{1 / 2^{\prime \prime}}$ & $1^{1 / 2 "}$ & $1^{1 / 2 "}$ & $1 "$ & $1 "$ & $1 "$ & $1 "$ \\
\hline
\end{tabular}

Çalışmada, arazinin yapısı, engel durumu ve su kaynağının debisi göz önüne alınarak sulanacak alan 10 parsele ayrılmıştır. Lateral boruların hesaplamalarıyla ilgili elde edilen veriler 
Çizelge 3'te verilmiştir. Elde edilen veriler doğrultusunda lateral uzunlukları 48-122m, lateral de bulunan başlık sayıları 19-42 adet, lateral debileri $0.82-1.53 \mathrm{~L} \mathrm{~s}^{-1}$, lateral boru çapları $32-40 \mathrm{~mm}$, lateral giriş basınçları 2.3-4.0 bar ve son olarak selenoid vana çapları $1^{\prime \prime}$ ve $1^{1 / 2}$ " arasında belirlenmiştir. Sistem kapasitesi $\mathrm{Hm}=45 \mathrm{~m}$ olarak bulunmuştur. Ayrıca, alanın toplam maliyeti $4960 \$$ olarak hesaplanmıştır.

\section{Peyzaj Alanının 2 ve 3 Boyutlu Olarak Görüntülenmesi}

Alan için tasarlanmış olan peyzaj ve sulama projeleri daha rahat anlaşılabilmesi için kendi içlerinde alanlara ayrılarak 2 ve 3 boyutlu olarak görüntüleri alınmıştır. Önce ayrılmış olan alanlara ait Autocad üzerinden 2 boyutlu peyzaj projesi ve ardından 3DsMax üzerinden tasarlanmış olan 3 boyutlu peyzaj ve başlık yerleşiminden alınan görüntüler konulmuştur. Bu işlemin ardından Autocad üzerinden 2 boyutlu sulama projesinden alınan görüntüler ( 3 boyutlu projede bakılan açı burada belirtilmiştir) ve 3DsMax programından alınmış olan 3 boyutlu sulama proje görüntülerine ait birer örnek sırasıyla, Şekil 4 ve Şekil 5'te gösterilmiştir. Ayrıca, çalışma alanının tamamına ait görüntü Şekil 6'da gösterilmektedir.

$\mathrm{Bu}$ çalışma kapsamında, sulama sisteminde kullanılan malzemelerin de 3 boyutlu olarak tasarlanması ve modellenmesi yapılmıştır. Ayrıca, suyun borulardan geçiş animasyonları da yapılmışıır. Çalışma alanında kullanılan malzemelere ilişkin bazı örnekler Şekil 7, 8 ve 9'da gösterilmiştir.

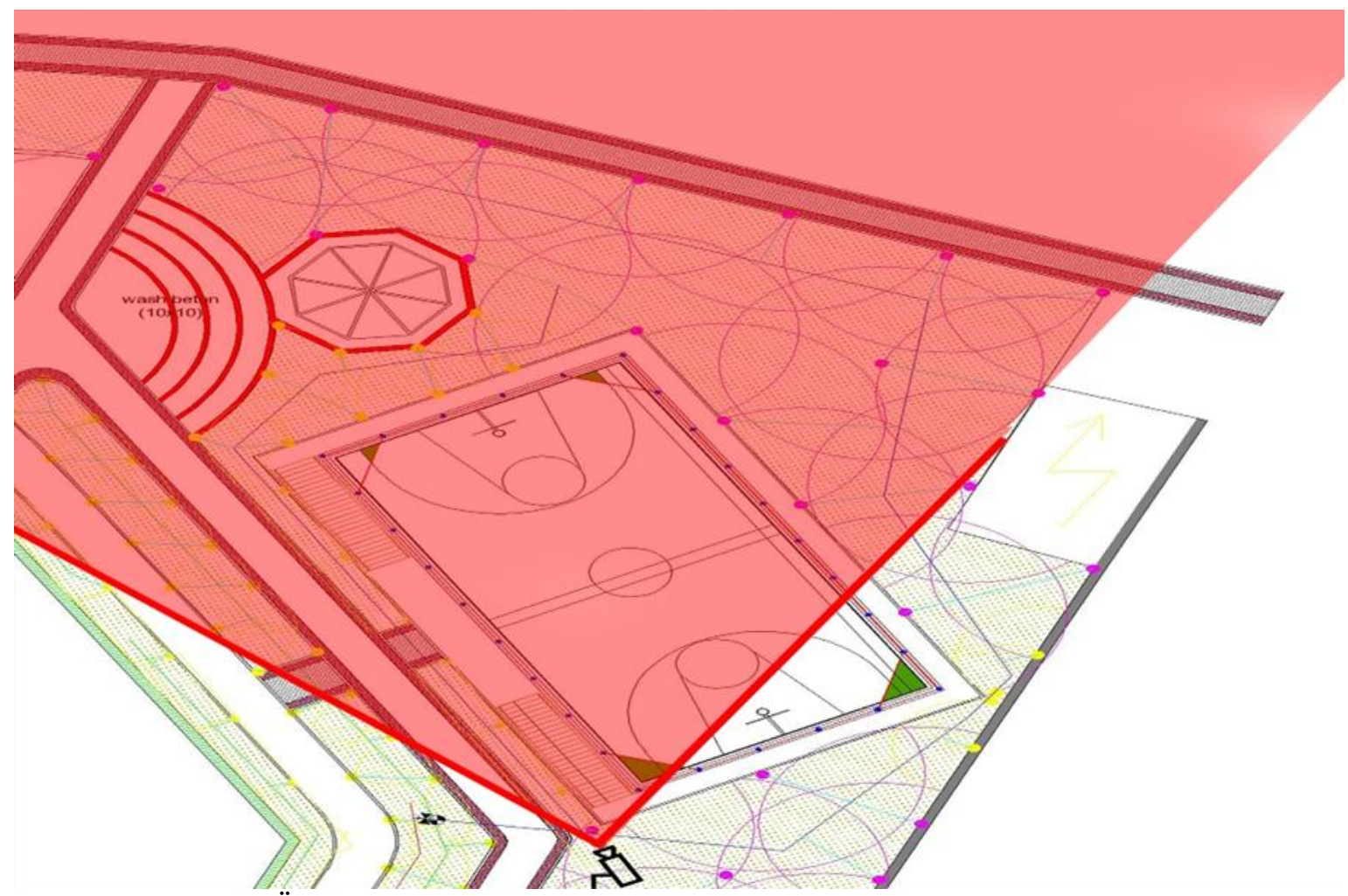

Şekil 4. Örnek olarak seçilen alanın sulama projesinin ve kamera açısının görüntüsü 
ÇOMÜ Zir. Fak. Derg. (COMU J. Agric. Fac.)

2020: 8 (1): 145-154

ISSN: $2147-8384$ / e-ISSN: 2564-6826

doi: 10.33202/comuagri.680427

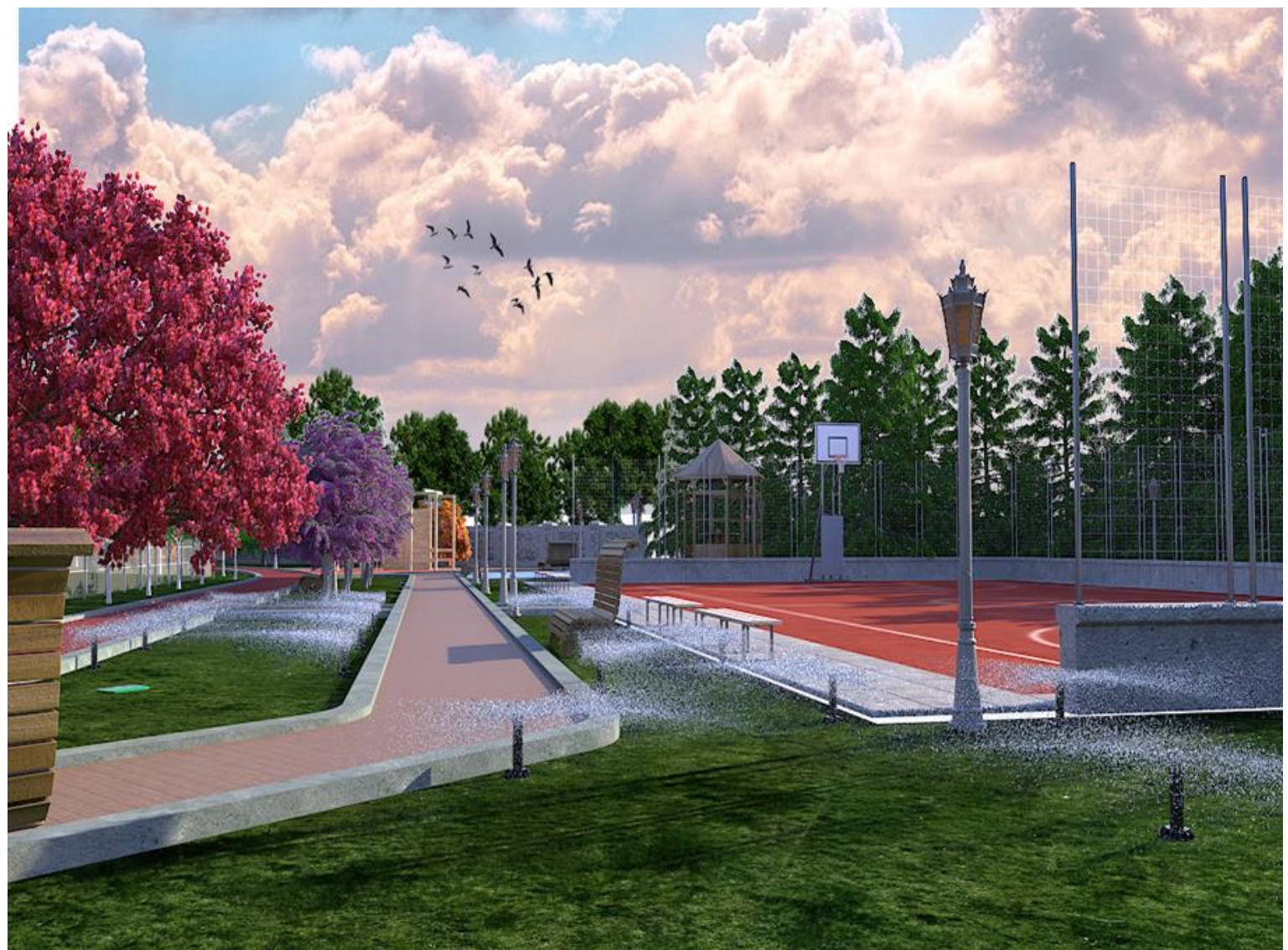

Şekil 5. Örnek olarak seçilen alanın sulama sistemi aktif hale geldikten sonraki 3 boyutlu görüntüsü

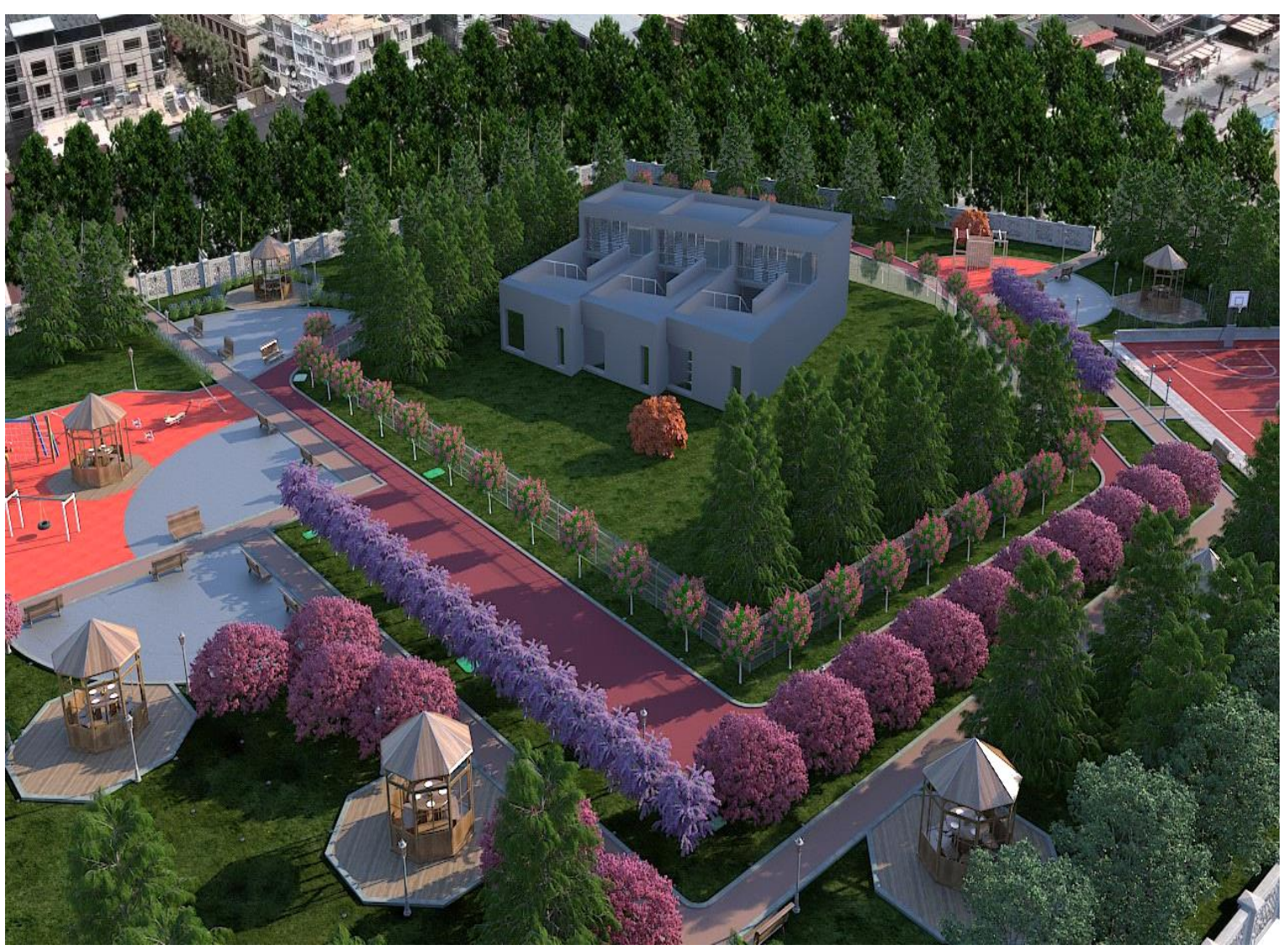

Şekil 6. Alanın 3DsMax programında çizilmiş 3 boyutlu görüntüsü 
ÇOMÜ Zir. Fak. Derg. (COMU J. Agric. Fac.)

2020: 8 (1): 145-154

ISSN: $2147-8384$ / e-ISSN: 2564-6826

doi: 10.33202/comuagri.680427

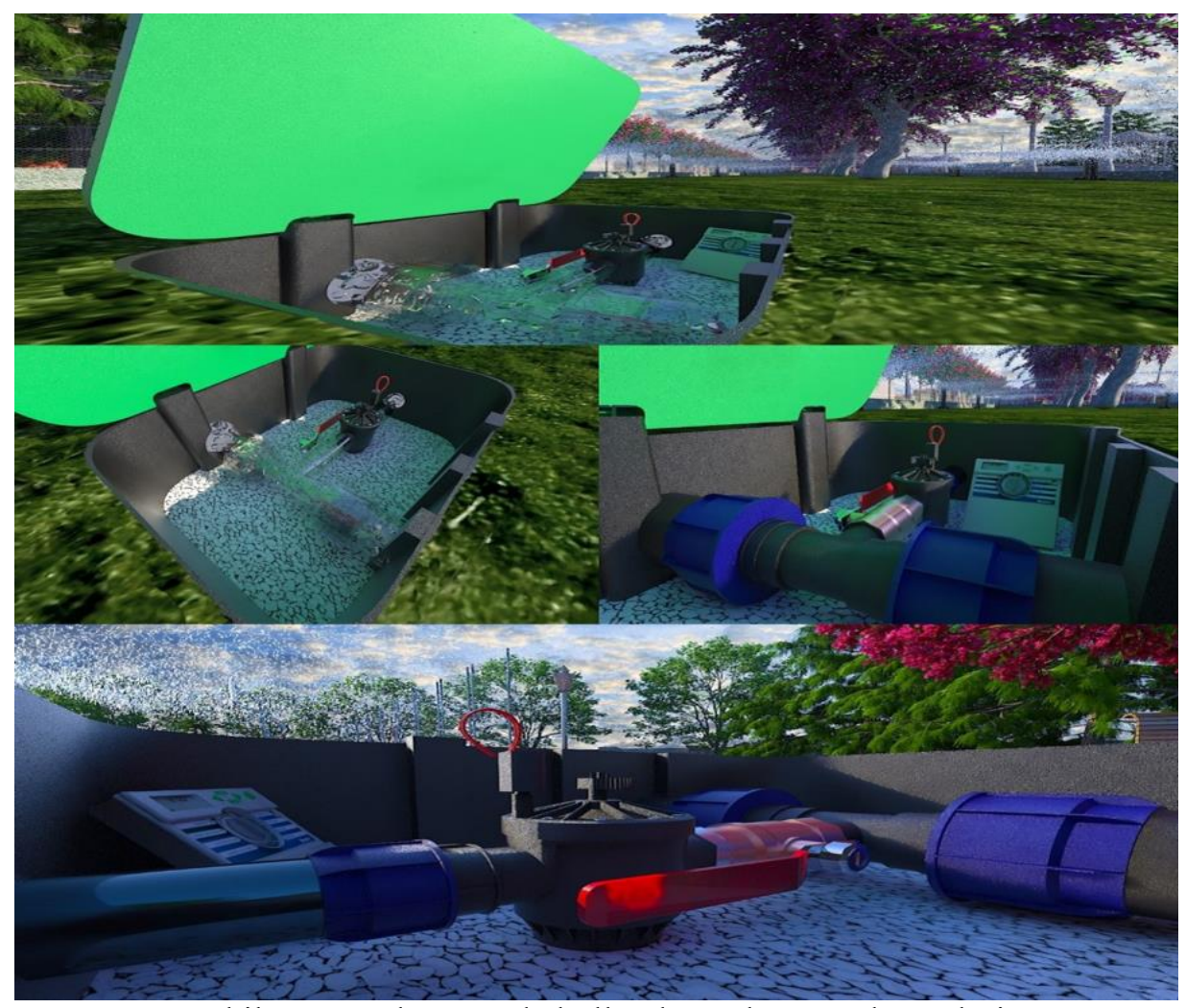

Şekil 7. Vana kutusunda kullanılan sulama malzemeleri

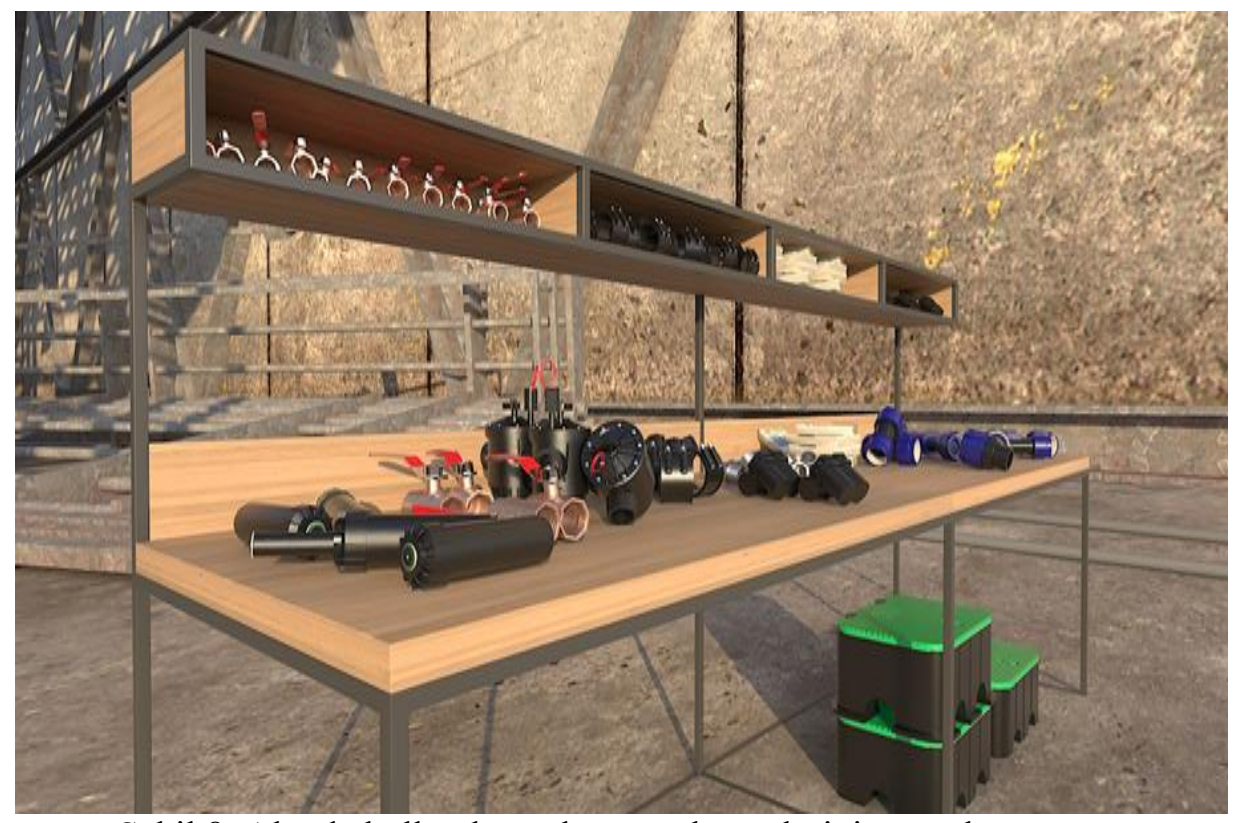

Şekil 8. Alanda kullanılan sulama malzemelerinin genel görünüşü 


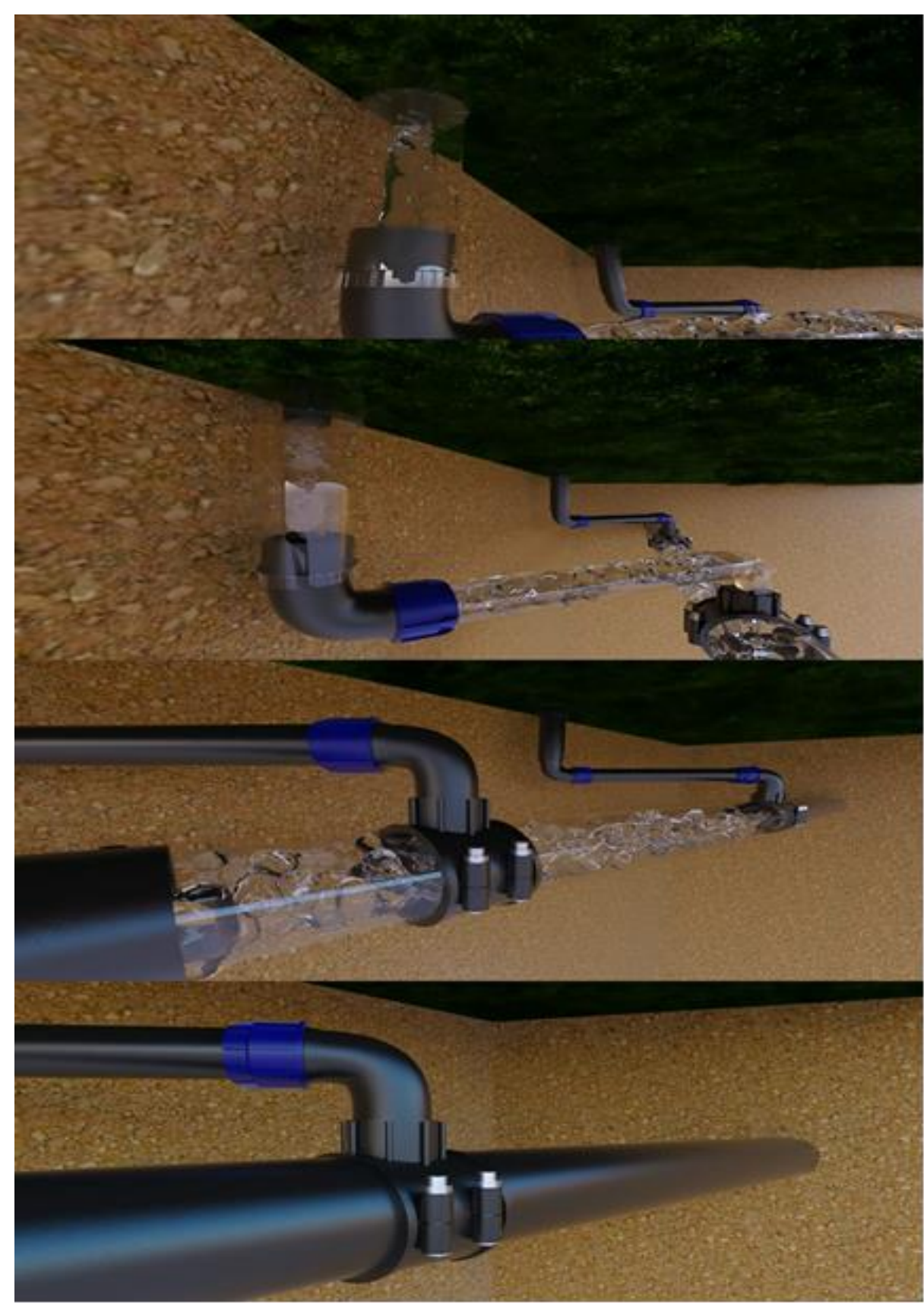

Şekil 9. Suyun borulardan geçiş animasyonu

Sulama sisteminde borularda suyun akış hızının ortalama olarak $1.5 \mathrm{~m} \mathrm{~s}^{-1}$ yi geçmemesi gerekmektedir. Özellikle $2 \mathrm{~m} \mathrm{~s}^{-1}$ yi geçtiği anda su, borular için ideal akış olan laminar akımdan türbülansa geçmektedir (Orta, 2009). Şekil 9'da suyun geçişinin net olarak gözükmesi açısından suyun akışı türbülans şeklinde gösterilmiştir.

\section{Sonuç ve Öneriler}

Çalışma kapsamında, Bursa İlinde bulunan Maltepe Su Deposu incelenmiş olup alana ait peyzaj, sulama ve 3 boyut projelendirilmesi yapılmıştır. Alana yapılmış olan tasarımlar çalışma alanının projelendirilmeden önceki mevcut durumu göz önüne alınarak gerçekleştirilmiştir. Çalışma alanı için hazırlanmış olan peyzaj projesi dikkate alınarak ayrıntılı bir şekilde sulama projesi yapılmıştır. Peyzaj ve sulama projeleri daha net anlaşılabilinmesi açısından 3 boyut programı olan 3Ds Max’te modellenmiş ve sulama sistemi projesinin toplam maliyeti verilmiştir. 
Tasarım yapılmadan önce alanda yapılmış olan gözlemlerde çalışma alanında daha önce hiçbir işlem yapılmadığı için alanda kendiliğinden bitmiş yabani otlar ve çalılar, çevre sakinlerinin düzensiz olarak ektiği veya çeşitli hayvanlar yardımıyla tohumların taşınmasından dolayı büyümüş olan meyveler (Malus spp.), atkestaneleri (Aesculus hippocastanum) ve çam ağaçları (Pinus brutia, Pinus pinea) saptanmıştır.

Peyzaj projesi tasarlanırken alanın güneyinde yer alan ve daha önce toprak almak amacıyla kazıldığ gözlemlenen düz alana, mahalle sakinlerinin aktivite yapabilmesi için çift potalı basketbol sahası konumlandırılmıştır. Alanın çevresinin mahalle olmasından dolayı güvenli bir yürüyüş ve koşu alanının bulunmadığı tespit edilmiş, bu duruma çözüm olarak alanda tartar zemin kullanılarak koşu ve yürüyüş parkuru tasarlanmıştır. Mahallenin yakınlarında başka park bulunmaması gözlemlendiğinden küçük ve orta yaşlı çocuklara hitap etmesi açısından 3 farklı park alanı tasarlanarak alanlara salıncak, tahterevalli, tırmanma duvarı ve kum alan yerleştirilmiştir. Yürüme alanlarının çevresinde yer yer oturma alanları tasarlanmıştır. Eğer projelendirme yapılırken çalışma alanın içerisindeki su deposunun etrafındaki güvenlik alanın daha dar tutulabilme durumu söz konusu olsaydı alana tasarlanacak projelerde daha sağlıklı ve ferah aktivite alanları elde edilebileceği söylenebilir.

Çalışma alanı için sulama projesi yapılmadan önce alanı etkileyen ve uygulamayı sonradan zora sokabilecek olan unsurlar belirlenmiştir (rüzgâr, toprak, mevcut ağaçlar vb.). Peyzaj projesinde tasarlanmış olan sert zeminler (yürüyüş yolları, çocuk oyun alanları vb.) ve bitkiler (mevcut veya sonradan yerleştirilmiş) dikkate alınarak alandan geçen ana borular, lateraller, vana kutuları, başlıklar tasarımlara zarar vermeyecek şekilde konumlandırılmıştır. Çalışma alanı toplam $6388 \mathrm{~m}^{2}$ olup yapılması düşünülen sulama projesinin toplam maliyet 4960 olarak saptanmıştır.

Sonuç olarak, peyzaj projelerinin 2 boyutlu hallerinin 3 boyutlu görsellerle desteklenerek alıcılara projenin detaylarının anlatılması pazarlama açısından büyük önem arz etmektedir. Yapılmış olan 2 boyutlu tasarımların 3 boyutlu görsellerle sunulması kullanıcılara, uygulayıcı ve alıcılara ciddi katk1 sağlayacak ve projenin anlaşılabilirliğini oldukça artıracaktır. Alıcının projeyi anlayıp gördüğü görsellerle projenin içerisindeymiş gibi hissetmesi pazarlamayı da kolaylaştıracaktır.

Not: Bu çalışma, Oğuzhan ALKAN'ın Yüksek Lisans tez çalışmasından hazırlanmıştır.

\section{Kaynaklar}

Aydın, Y., (B.T). Temiz su kaynaklarının hızla tükenmesinin sebepleri nelerdir? Erişim Tarihi: 10 Ekim 2019, https://www.biyologlar.com/temiz-su-kaynaklarinin-hizla-tukenmesinin-sebepleri-nelerdir-

Demircan, U., 2017. İstanbul'da kişi başına düşen yeşil alan bir metrekare. Erişim Tarihi: 10 Ekim 2019, https://onedio.com/haber/-neden-esmiyor-diye-sorarken-iki-kere-dusunun-istanbul-da-kisi-basinadusen-yesil-alan-bir-metrekare-779317

Demirel, K., Yıldırım, M., Çamoğlu, G., 2006. Çanakkale ili belediye sınırları içerisindeki peyzaj alanlarında sulama sistemlerinin projelenmesi ve işletilmesindeki hatalar. Atatürk Üniversitesi Ziraat Fakültesi Dergisi. 37(1): 81-90.

Demirel, K., Çamoğlu, G., Sağlık, A., Kelkit, A., Genç, L., 2018. Çanakkale ili peyzaj alanlarındaki sulama sistemlerinin incelenmesi: Özgürlük Parkı ve Halk Bahçesi. Uludağ Üniversitesi Ziraat Fakülte Dergisi. 32(1): 127-139.

Gönül Altay, Ö., 2019. Çanakkale İlindeki Büyük Ölçekli Peyzaj Alanlarının Sulama Sistemlerinin İncelenmesi. Çanakkale Onsekiz Mart Üniversitesi Fen Bilimleri Enstitüsü, Peyzaj Mimarlı̆̆ı Anabilim Dalı, Yüksek Lisans Tezi. $135 \mathrm{~s}$.

İşbilir, H., Erdem, T., 2012. Rekreasyon alanı sulama projelerinin tasarım ve uygulama aşamalarında ortaya çıkan sorunlar ve çözüm önerileri. Tekirdağ Ziraat Fakültesi Dergisi. 9(2): 57-66.

Küçüksayan, C., Gülez, S., Cengiz, B., 2011. Peyzaj alanlarında otomatik sulama sistemi uygulamasının irdelenmesi. Ankara Kenti Örneği. Bartın Orman Fakültesi Dergisi. 13(19): 52-62.

Orta, H., 2009. Rekreasyon Alanlarında Sulama. Namık Kemal Üniversitesi Ziraat Fakültesi, Tekirdağ.

Özden, M.A., 1993. Peyzaj Çalışmalarında Farklı Sulama Tekniklerinin Uygulanabilirliği Üzerine Bir Araştırma. Ankara Üniversitesi, Fen Bilimleri Enstitüsü, Peyzaj Mimarlı̆̆ı Anabilim Dalı, Yüksek Lisans Tezi. $138 \mathrm{~s}$.

Öztürk O., (10 Temmuz 2014). Mimarlar İçin En İyi 7 Program. 25.12.2017, http://www.elektrikport.com/teknik-kutuphane/mimarlar-icin-en-iyi-7program/12190

URL 1. (b.t.). Erişim Tarihi: 9 Temmuz 2019. https://www.google.com.tr/intl/tr/earth 